\title{
Geotechnical effects of polymer treatment on tailings - state of knowledge review
}

\author{
D Reid The University of Western Australia, Australia \\ AB Fourie The University of Western Australia, Australia
}

\begin{abstract}
As the trialling and application of polymer treatment of tailings at the point of discharge has increased, so have studies to assess the effects of polymer treatment on subsequent tailings geotechnical behaviour. A review of the publically available studies is presented, including laboratory and in situ tests on mature fine tailings, comparison of consolidation tests on a range of tailings types, and a large comparative study on a synthetic tailings that included laboratory and cone penetrometer testing. The data available indicate that polymer treatment can have significant effects, including changes to rate of consolidation, density of a material at a given effective stress, location of critical state line, undrained shear strength at a given density, and strain rate effects. Also, while there are less data on this topic, there is evidence that shearing, and some forms of ageing, can reduce the effects of polymer treatment on geotechnical properties. Penetrometer test comparisons indicate that the increased rate of consolidation for polymer-treated material can result in quite different penetrometer responses owing to drainage effects.
\end{abstract}

Keywords: inline flocculation, polymer treatment, consolidation, undrained strength

\section{Introduction}

Attempts to improve the dewatering behaviour of tailings through the addition of polymers at the point of discharge appear to have been first attempted in the early 1980s on coal tailings (Backer \& Busch 1981; Stewart et al. 1986). Significant interest has developed more recently, with a variety of applications on a number of tailings types over the past 10 years (Cooling \& Beveridge 2015; Jeeravipoolvarn et al. 2009; Riley et al. 2015). An area of particular focus has been mature fine tailings (MFT), which is the very fine tailings resulting from processing oil sands, owing to the closure challenges related to that material type. End of pipe flocculant addition has also been examined for application in the dredging industry (Manzotti et al. 2014; Van Impe et al. 2009). Terminology for this technology varies, with it having been referred to as inline flocculation, secondary flocculation and polymer treatment. Herein it is referred to as polymer treatment (PT).

While initial impetus for PT is generally focused on rapid initial water release, reduction in particle segregation, and near-surface strength gain (i.e. for equipment access and covering works), implementation of PT can have ongoing effects on the geotechnical behaviour of tailings compared to the same material when in an untreated (UT) state. The ramifications of flocculation on tailings' geotechnical behaviour is important with respect to the stability of tailings storage facilities (TSFs) should the strength of PT tailings be relied upon, for example, when utilised in an upstream-raised TSF, or should the tailings form part of a steepened beach without containment. Further, PT effects on ongoing consolidation behaviour will impact how a TSF consolidates over time and the densities achieved. The effects of PT on geotechnical properties of tailings are of importance as this technology is more widely considered and applied. 
This paper reviews and summarises the publicly available literature on the effects of PT with respect to self-weight consolidation, strength, penetrometer response, and the longevity and/or sensitivity of such changes to shear and ageing. It is noted that the works summarised here are generally confined to studies carried out in a geotechnical engineering context - i.e. where significant effective stresses are present in the soil. It is noted that significant studies of the effects of flocculants in dewatering behaviour (i.e. in thickeners) have also been carried out (Farrow et al. 2000; Spehar et al. 2015), including studies of the effects of shearing on the flocculated structure (Gladman et al. 2005, 2010). It is further noted that the majority the studies referenced herein involved preparation of PT material in a laboratory setting with minimal shearing to the specimens (beyond that required to mix the PT). While these represent an important starting point in such research - i.e. to allow assessment firstly of what effects PT may induce with negligible breakdown from shear, all tailings deposited on a beach will be exposed to some degree of post-treatment shear. Some initial studies have begun to quantify the effects of shear and are included in the discussion.

\section{Observed effects in literature}

\subsection{Atterberg limits}

A number of observations of changed Atterberg limits following PT have been documented (Beier et al. 2013; Jeeravipoolvarn et al. 2009; Manzotti et al. 2014; Reid \& Fourie 2016). In particular, liquid limit is typically seen to increase - implying a higher undrained shear strength at a given density (at least at low stresses/densities). Further, modification of Atterberg limits suggests that PT is likely to alter some intrinsic soil properties of slurries with plasticity, similar to the effects of different pore fluid chemistry (e.g. salt, ionic strength and $\mathrm{pH}$ ).

\subsection{Density}

The density that a tailings deposit achieves is of critical importance to TSF design. However, the realised density achieved in a TSF is a result of a number of factors, including (i) density versus effective stress characteristics of the material, (ii) hydraulic conductivity versus density characteristics of the material, (iii) rate of rise (RoR), and (iv) drainage conditions, particularly on the floor of the TSF. Attempts to account for a number of these components when assessing the effects of PT have been made, and are discussed subsequently in this paper. However, for the purpose of comparing the effect of PT on density, the comparison will initially be made as to the 'final' density achieved under a given magnitude of effective stress - i.e. point (i).

A number of laboratory comparisons have been made to assess the effects of PT on density under a given magnitude of effective stress, as summarised in Table 1. For most examples cited, PT resulted in a lower ultimate density than untreated tailings when compared in this way. The effect of this observation on actual realised densities within a TSF are discussed later in this paper. The devices used to measure consolidation behaviour include the oedometer, seepage-induced consolidation test (SICT), direct simple shear (DSS), triaxial, slurry consolidometer, Rowe Cell, and constant rate of strain (CRS) consolidation device. Testing has been carried out on a wide range of tailings and soils types. 
Table 1 Summary of PT effects on density under given effective stress

\begin{tabular}{llll}
\hline Reference & Test device & Material type & Effect on density \\
\hline Jeeravipoolvarn et al. (2009) & $\begin{array}{l}\text { Slurry } \\
\text { consolidometer, } \\
\text { settling tests }\end{array}$ & MFT & Decrease \\
Van Impe et al. (2009) & SICT & Dredged sludge & Increase \\
Azam (2011) & $\begin{array}{l}\text { Slurry } \\
\text { consolidometer }\end{array}$ & Laterite slurry & $\begin{array}{l}\text { Generally increase (varied } \\
\text { based on polymer type) }\end{array}$ \\
Yao (2012) & Oedometer & MFT & Decrease \\
Reid and Fourie (2012) & Triaxial & Kaolin & Decrease \\
Manzotti et al. (2014) & CRS & Dredged silt & Decrease \\
Beveridge et al. (2015) & Slurry & Mineral & Decrease \\
consolidometer & sands/slimes & \\
Riley et al. (2015) & Slurry & Copper and gold & Varied \\
consolidometer & tailings & \\
Znidarcic et al. (2015) & SICT & MFT & Decrease \\
Gholami and Simms (2015) & DSS & MFT & Decrease \\
Reid and Boshoff (2015) & DSS & Laterite nickel & Decrease \\
Reid et al. (2015a) & tailings & Iron ore tailings & Decrease \\
Reid and Fourie (2016) & Slurry & Low plasticity & Decrease \\
& consolidometer & 'synthetic' tailings & \\
\hline
\end{tabular}

\subsection{Hydraulic conductivity}

Similar to density, hydraulic conductivity has also been measured by a number of researchers, as outlined in Table 2. Many of the studies cited are the same as those previously listed in Table 1, as it is typical for density and hydraulic conductivity to be measured during the same test.

The results indicate that PT generally results in an increased hydraulic conductivity at a given density when compared to UT materials. Such a difference at the same density suggests that PT is resulting in a modified spatial and geometric configuration of the elements that make up the soil - i.e. the soil fabric. As will be seen subsequently in this paper, many of the changes induced by PT are similarly indicative of fabric changes. The combination of the changes of PT on density and hydraulic conductivity also suggest that assessing the potential impact on average in situ density through implementation of PT technology cannot be determined in isolation through laboratory element tests. Methods to carry out site-specific assessments using additional means are discussed later in this paper. 
Table 2 Summary of PT effects on hydraulic conductivity at given density

\begin{tabular}{|c|c|c|c|}
\hline Reference & Test device & Material type & $\begin{array}{l}\text { Effect on hydraulic } \\
\text { conductivity at given density }\end{array}$ \\
\hline Jeeravipoolvarn et al. (2009) & $\begin{array}{l}\text { Slurry } \\
\text { consolidometer, } \\
\text { settling tests }\end{array}$ & MFT & Increase \\
\hline Van Impe et al. (2009) & SICT & Dredged sludge & Increase \\
\hline Azam (2011) & $\begin{array}{l}\text { Slurry } \\
\text { consolidometer }\end{array}$ & Laterite slurry & Increase \\
\hline Yao (2012) & Oedometer & MFT & Increase \\
\hline Reid and Fourie (2012) & $\begin{array}{l}\text { Triaxial and } \\
\text { Rowe Cell }\end{array}$ & Kaolin & No change \\
\hline Manzotti et al. (2014) & CRS & Dredged silt & No change \\
\hline Beveridge et al. (2015) & $\begin{array}{l}\text { Slurry } \\
\text { consolidometer }\end{array}$ & $\begin{array}{l}\text { Mineral } \\
\text { sands/slimes }\end{array}$ & Increase \\
\hline Riley et al. (2015) & $\begin{array}{l}\text { Slurry } \\
\text { consolidometer }\end{array}$ & Various & Increase \\
\hline Znidarcic et al. (2015) & $\mathrm{SICT}$ & MFT & Increase \\
\hline Reid and Fourie (2016) & $\begin{array}{l}\text { Slurry } \\
\text { consolidometer }\end{array}$ & $\begin{array}{l}\text { Low plasticity } \\
\text { 'synthetic' tailings }\end{array}$ & Increase \\
\hline
\end{tabular}

\subsection{Undrained shear strength}

Undrained strength is often the most critical form of tailings strength with respect to both global embankment stability, and to stability during cover placement. Therefore, it has been the subject of much testing with respect to PT effects. However, to assess the effects of PT, it is first important to differentiate two ways of representing undrained shear strength:

1. Measures of undrained shear strength $\left(s_{u}\right)$ at a given density. This approach is required when comparing, for example, surficial shear vane results where defining the effective stresses acting on the tested material is impractical. However, this value can also be obtained from laboratory element tests, where both the absolute $s_{\mathrm{u}}$ value and density of the specimen are known.

2. Undrained shear strengths at a given effective stress condition - most typically reported as an undrained strength ratio, with vertical effective stress $\left(\sigma_{v}^{\prime}\right)$ as the reference stress condition (i.e. $s_{u} / \sigma_{v}^{\prime}$ ). Such a measure can be obtained from laboratory element and penetrometer tests. It is the most relevant value of undrained strength with respect to most forms of stability analysis.

The effects of PT on the undrained shear strength of a wide range of materials are presented in Table 3 , with the effects under both criteria (1) and (2). Undrained shear strengths were measured by vane shear (laboratory or field application), triaxial, DSS, or inferred from fall cone results. In all examples identified, PT is seen to result in an increase in $s_{u}$ at a given density. Such an increase is consistent with increases to shear yield stress due to flocculation in tailings thickening and filtration (e.g. Adkins et al. 2012). However, owing to the interacting effects of PT on both density and $s_{u}$ at a given effective stress, the resulting $s_{u} / \sigma^{\prime}{ }_{v}$ following PT is often similar to that in a UT condition. 
Table 3 Summary of effects on undrained shear strength

\begin{tabular}{lllll}
\hline Reference & Test device & Material type & $\begin{array}{l}\text { Effect on } \boldsymbol{s}_{\mathrm{u}} \text { at } \\
\text { given density }\end{array}$ & $\begin{array}{l}\text { Effect on } \\
\boldsymbol{s}_{\mathrm{u}} / \boldsymbol{\sigma}_{\mathrm{v}}{ }_{\mathrm{v}}\end{array}$ \\
\hline $\begin{array}{l}\text { Jeeravipoolvarn et al. (2009) } \\
\text { Yao (2012) }\end{array}$ & Vane shear & MFT & Increase & - \\
Reid and Fourie (2012) & Vane shear & MFT & Increase & - \\
Beier et al. (2013) & Triaxial & Kaolin & Increase & Increase \\
Manzotti et al. (2014) & Vane shear & MFT & Increase & - \\
Cooling and Beveridge (2015) & Vall cone & Dredged silt & Increase & - \\
Gholami and Simms (2015) & Triaxial and DSS & Bauxite residue & Increase & - \\
Reid et al. (2015a) & DSS & Iron ore tailings & Increase & No change \\
Reid and Fourie (2016) & Triaxial & Low plasticity & Increase & No change \\
& & 'synthetic' tailings & & Increase \\
Reid and Fourie (2017a) & DSS & Low plasticity & Increase & No change \\
& & 'synthetic' tailings & & \\
\hline
\end{tabular}

Whereas the above data represents the measurements of undrained shear strength obtained in various studies, undrained shear strength is a geotechnical property that is sensitive to a number of factors. In particular, measured undrained strength is a function of shearing rate. This means that tests carried out quickly (i.e. a hand shear vane) will, all else being equal, give a lower strength than a 'slow' laboratory test such as the DSS. This was discussed by Gholami and Simms (2015) when comparing their laboratory results to previous shear vane testing outlined by Beier et al. (2013). Further, while generally all materials with some plasticity exhibit strain rate dependence, there is evidence from comparison testing that PT may increase this strain rate dependency when compared to that same material in a UT state (Reid \& Fourie 2017a). Such an effect would indicate caution is required in placing reliance upon a hand shear vane when concluding that PT results in a higher undrained shear strength, as the rate of shearing of a hand vane is much higher than that typically applied to undrained stability analyses.

Separate to strain rate dependence (in fully undrained shearing), the potential for some field tests to be affected by partial drainage during shearing exists as the rate of consolidation of a material increases. This means that caution is necessary in examining, say, comparison of hand shear vane data for a material where the increase in consolidation rate resulting from PT could change the drainage conditions during hand shear vane testing. The effects of partial drainage on penetrometer response is discussed later in this paper.

\subsection{Critical state conditions}

The critical state line (CSL) represents an important reference point to define a material's likely behaviour under shear (i.e. contractive or dilative). As such, was PT to affect the resulting CSL, this would be an important consideration in tailings design. The previously discussed undrained triaxial tests carried out by Reid and Fourie (2016) on a low-plasticity synthetic tailings were part of a larger test program that also included drained tests. Together, this series of tests on PT and UT material allowed the CSL for both to be defined (Figure 1).

The results strongly suggest that for the tested material, PT changes the material's CSL. This was consistent across the three triaxial test types utilised - isotropic undrained $(\mathrm{CIU}), K_{0}$ undrained $\left(C K_{0} \mathrm{U}\right)$ and isotropic drained (CID). Further, the inferred variation to the CSL suggested in Figure 1 is generally consistent with the other testing results on UT and PT material in the same program. These outcomes indicate that the effects of PT on resulting CSL should be considered when critical state techniques (Li et al. 2009; McPhail et al. 2004) are applied to assess the stability of a steepened tailings beach. 


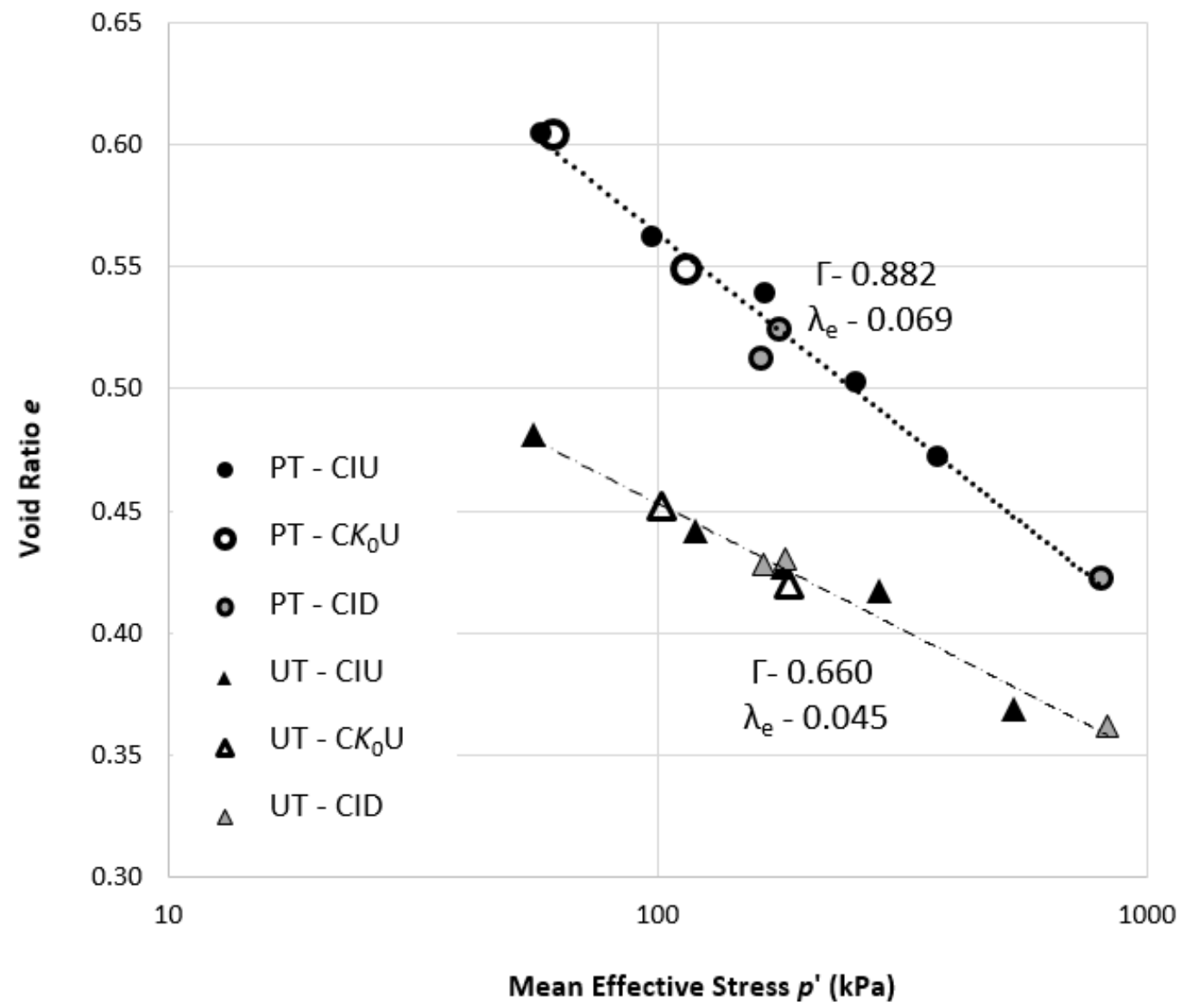

Figure 1 Inferred CSLs for UT and PT synthetic slurry (after Reid \& Fourie 2016)

\subsection{Cyclic resistance}

Cyclic liquefaction is a major potential issue for a steepened tailings beach, as it is one of the primary trigger methods for strength loss leading to flow liquefaction. Further, cyclic liquefaction behaviour is affected by a number of material properties such as density, fabric, and deposit age. Three published examples of cyclic testing are available to enable comparison between PT and UT material - testing by Reid and Boshoff (2015) on laterite nickel samples, Reid et al. (2015a) on iron ore tailings, and by Reid and Fourie (2017a) as part of their study of PT effects on a low-plasticity synthetic tailings. The results of these three test programs are summarised together in Figure 2.

Of the results, testing on the iron ore and synthetic tailings indicated negligible effect of PT on resulting cyclic resistance - despite the PT material being at a lower density as inferred from mass of solids and volume of the specimen in both cases. However, as cyclic resistance can be affected by both density and fabric, it appears that the fabric induced by PT for those materials is increasing the cyclic resistance (thus presumably counteracting the effect of a lower density). Alternatively, the lateritic nickel tailings indicate a lower cyclic resistance following PT. This may suggest that the effects of PT on fabric, and the manifestation of these effects on cyclic resistance, may be material-specific. As only three materials have undergone comparative cyclic testing, it may be premature to draw conclusions from the available results. 


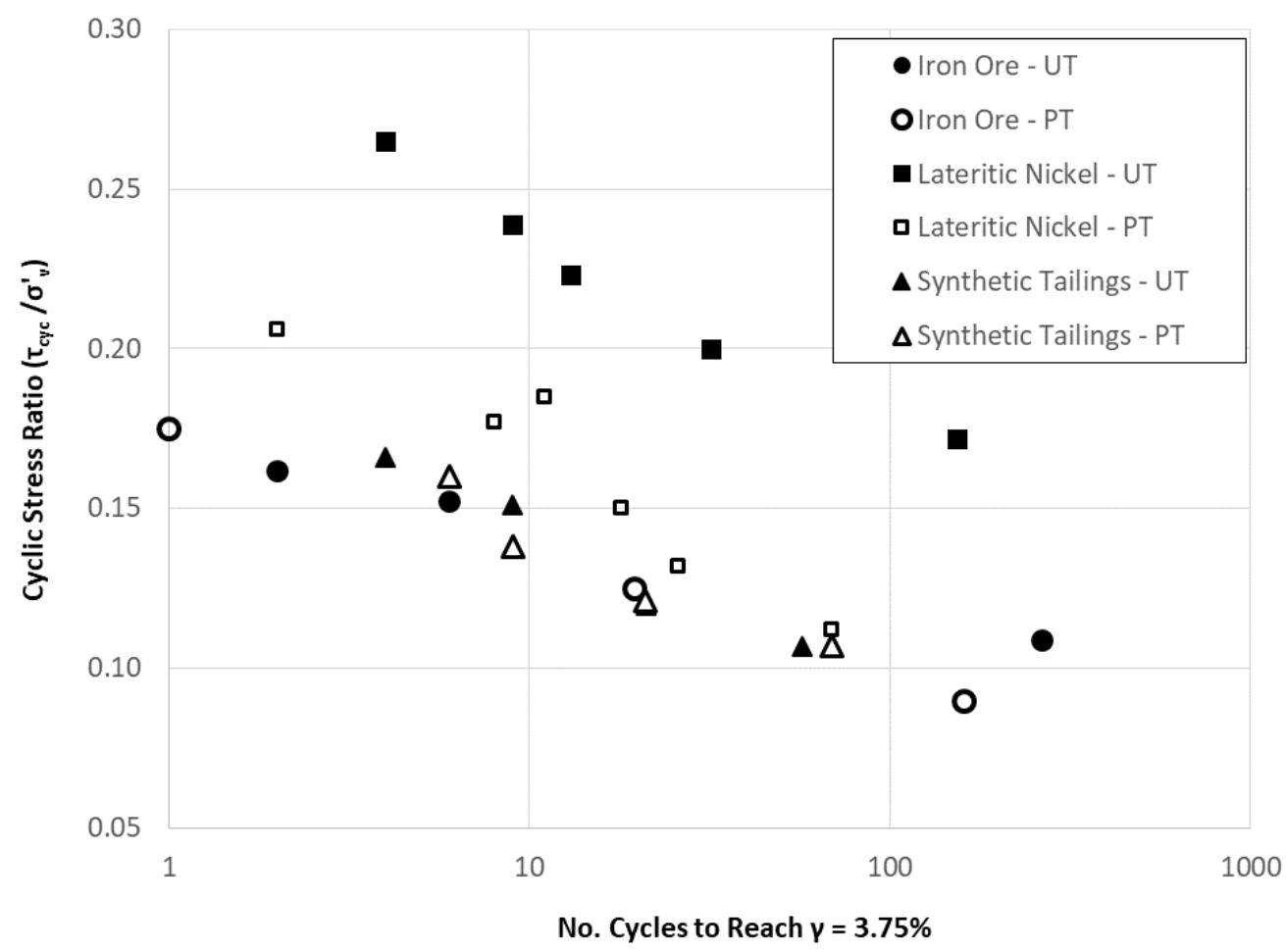

Figure 2 Cyclic behaviour of lateritic nickel, iron ore, and 'synthetic' tailings in PT and UT condition

\subsection{Brittleness and/or post-cyclic strength loss}

The strength of a tailings after seismic loading, and/or static triggering of strain softening behaviour, is often the controlling strength for thickened TSFs with a steepened beach (Li et al. 2009; Seddon 2007). However, there remains some inconsistency in the geotechnical and tailings professions regarding how to assess the strength after seismic loading, and whether such a strength could be strain-dependent for some materials (for detailed discussion, see Reid \& Fourie 2014). For example, penetration-based empirical correlations (e.g. Olson \& Stark 2002) are based primarily on sandy silts and silty sands with little to no plasticity, and the post-liquefaction strengths inferred from the case histories represent the likely 'minimum' strength. They also include likely field-scale effects such as void ratio redistribution. Alternative to the above approach, for materials of moderate plasticity, it is common to see the post-seismic strength developed as a function of strain (Castro 2003; Stark et al. 2012), with the suggestion that at high strains the strength would reduce to the residual/remoulded strength. This value is often derived from residual shear vane testing (e.g. Beier et al. 2013). This conceptual framework would seem to suggest that post-cyclic testing in, for example, a DSS device, could be of relevance for developing potential post-seismic strengths (should the likely strain during a seismic event be estimated accurately).

For the purpose of the present discussion, two forms of testing to assess the effects of PT on the brittleness and/or post-cyclic strength loss of tailings are outlined:

- Beier et al. (2013) outlined shear vane testing on MFT that suggests much greater brittleness for PT deposits.

- Post-cyclic test comparisons using a DSS device outlined by Reid and Boshoff (2015), Reid et al. (2015a), and Reid and Fourie (2017a). Most of this testing did not suggest an increase in post-cyclic strength loss in PT samples.

In general, while data on the effects of PT on strength loss have been obtained, the general uncertainties in the geotechnical profession regarding methods and theories for the development of post-seismic strength add significant uncertainty in this area. Further research on these issues will likely be required to enable confident assessment of the brittleness of PT deposits with large, steepened beaches. 


\subsection{Penetrometer behaviour}

Owing to the limited number of sites operating PT on a full scale, there is relatively little comparative data on cone penetration tests (CPT) and full flow pentrometer (ball, T-bar) tests in PT and UT deposits of a similar material. Further, owing to the difficulty in creating two deposits from identical material, where one has undergone PT and one is UT, direct comparisons may always be a challenge. Two examples, one full-scale and one using miniature penetrometers, were identified:

- Da Silva (2011), who reported comparative CPT probes in UT and trial deposition PT zones, with the latter exhibiting much higher tip resistance and negligible excess pore pressure generation during probing. These results may indicate higher effective stresses (from faster consolidation) and/or the effects of higher drainage rates in the PT material resulting in partially drained CPT penetration.

- Reid and Fourie (2017b) carried out a series of miniature T-bar and CPT probes in beam centrifuge strongboxes on their synthetic slurry material in both a UT and PT condition.

The results obtained by Reid and Fourie (2017b) are summarised in Figure 3 as normalised penetration resistance $Q$ against normalised penetration velocity $V$ (Finnie $\&$ Randolph 1994). A wide range of penetration velocities were used in this study to explore the interaction of the different drainage rates of PT and UT material and penetration resistance. The testing indicated similar penetration resistance during slow (i.e. drained) penetration, whereas at increasing velocity PT exhibited dilative behaviour and UT contractive behaviour (and hence lower $Q$ ). The reasons for this discrepancy are not clear at this time, as laboratory element tests of PT material exhibited contractive behaviour when in a normally consolidated state similar to that within the beam centrifuge. Clearly, more study of penetration response following PT is required.

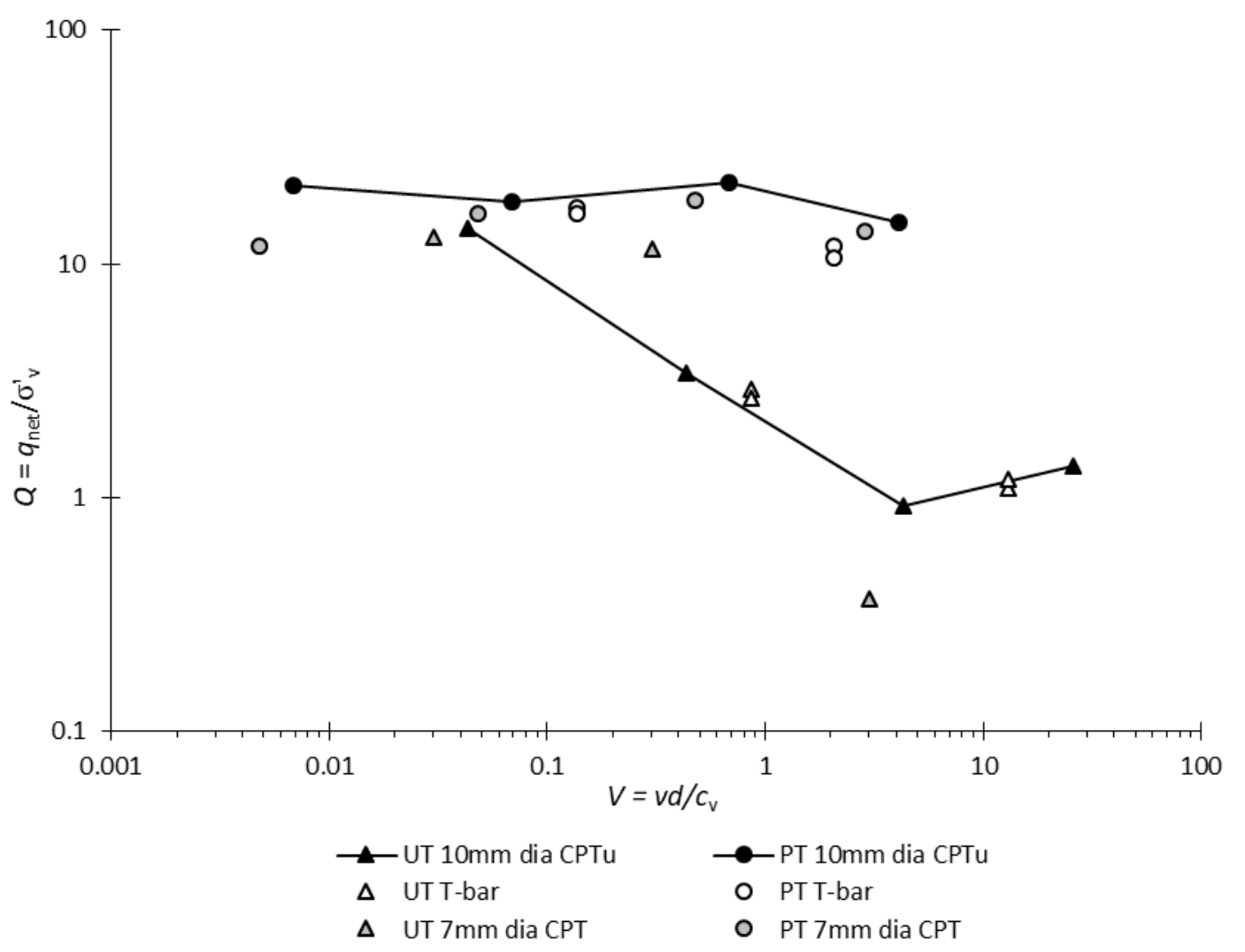

Figure 3 Normalised penetrometer resistance against normalised penetration velocity (after Reid \& Fourie 2017b) 


\subsection{Shear and ageing effects}

In the previously cited laboratory studies, the PT materials were generally prepared without additional shearing beyond that necessary to mix the polymer. However, deposition on a tailings beach (i.e. after PT occurs in a pipe, for example) will result in additional shearing of the material. The magnitude of shear is also likely to vary along a beach, with additional shearing occurring as the slurry runs down the beach, as water flows through and around the flocs and as flocs consolidate. Such shearing may affect the subsequent geotechnical performance of the material.

Two studies have specifically examined the potential for shearing, after PT mixing, to affect geotechnical properties:

- Jeeravipoolvarn et al. (2014) on MFT samples.

- Reid and Fourie (2015) on their synthetic low-plasticity tailings material.

Both studies indicated that shearing of the PT material after initial mixing generally reduced the changes that occurred - i.e. the 'sheared' PT samples exhibited behaviour closer to UT material. It appears that shearing induces a breakdown of the network structure developed by PT, and hence reduction of the changes resulting from this network structure. The changes seen in geotechnical consolidation properties are similar to those observed in particulate suspension dewatering studies (e.g. Gladman et al. 2005) and on rheological studies of PT tailings sampled along an active beach (e.g. Charlebois 2012).

Separate to shearing during deposition is the question of whether, over time, chemical degradation of polymers may result in changes to the material behaviour. An interesting laboratory study that provides some preliminary information is the work of Mao and Fahey (1999) on the use of flocculants in reconstituting a moderate plasticity silty clay calcareous soil from the North West Shelf of Western Australia. For this material, it was found to be difficult to prepare reconstituted samples as loose as found in situ (a common problem). Therefore, Mao and Fahey mixed the material with flocculant as part of the reconstitution process, which resulted in lower densities at a given vertical effective stress. The densities for the flocculated samples then more closely resembled tube samples - although still giving higher shear strengths.

On the basis of their initial results, Mao and Fahey (1999) theorised that the flocculants themselves were causing an increase in strength. They then stored some flocculated samples in an $80-90^{\circ} \mathrm{C}$ water bath, based on their previously observed degradation of the flocculant solution under such temperatures. This heat treatment reduced the strength of the flocculated samples, possibly implying that flocculants themselves can increase strengths even at effective stresses $>100 \mathrm{kPa}$. However, it is not entirely clear how applicable these observations are to PT tailings. For example, Mao and Fahey did not carry out control tests to assess if such a high temperature water bath affected the behaviour of the unflocculated calcareous soil. Furthermore, the flocculant used in their work, Magnafloc 919 from Allied Colloids Australia (now BASF Australia), is not of a type commonly applied in PT at the point of tailings discharge. It seems clear from this review that further study is necessary as to the potential for the effects of PT to degrade or change over time if the polymers themselves degrade.

\section{Self-weight consolidation assessments}

The majority of the consolidation test comparisons previously outlined indicated PT resulted in lower densities at a given magnitude of effective stress, and higher hydraulic conductivity at a given density. As the average density developed in a deposit is a function of both of these properties, assessing the effect of PT on density therefore requires more than laboratory element test comparisons. At least three studies have taken consolidation test result comparisons and carried out finite strain consolidation simulations to assess the difference in idealised PT and UT deposits (Jeeravipoolvarn et al. 2014; Reid et al. 2015b; Znidarcic et al. 2015). The studies of Jeeravipoolvarn et al. (2014) and Znidarcic et al. (2015) were focused on MFT which generally has a very low hydraulic conductivity in a UT state, and as such, PT was seen to increase the density realised in the deposit. Reid et al. (2015b) carried out modelling based on their previous testing of a 
low-plasticity synthetic tailings, which had a much higher hydraulic conductivity than MFT (either in a UT or PT state). Modelling related to the synthetic tailings was carried out across a range of deposition rates, which were quantified using the term 'slurry RoR' - i.e. the rate of rise in the deposit should no hindered settling or self-weight consolidation occur. The results of that study in terms of average density versus rate of deposition (i.e. slurry RoR) for UT and PT material are summarised in Figure 4. The plot suggests that at higher deposition rates, the higher hydraulic conductivity of the PT material outweighs the higher final dry densities (at a given vertical effective stress) of the UT material.

In general, the available examples of self-weight consolidation modelling of idealised PT and UT deposits indicates the importance of site and material-specific considerations when assessing the potential benefits of implementing PT, and points to some conceptual frameworks to enable such assessments to be made.

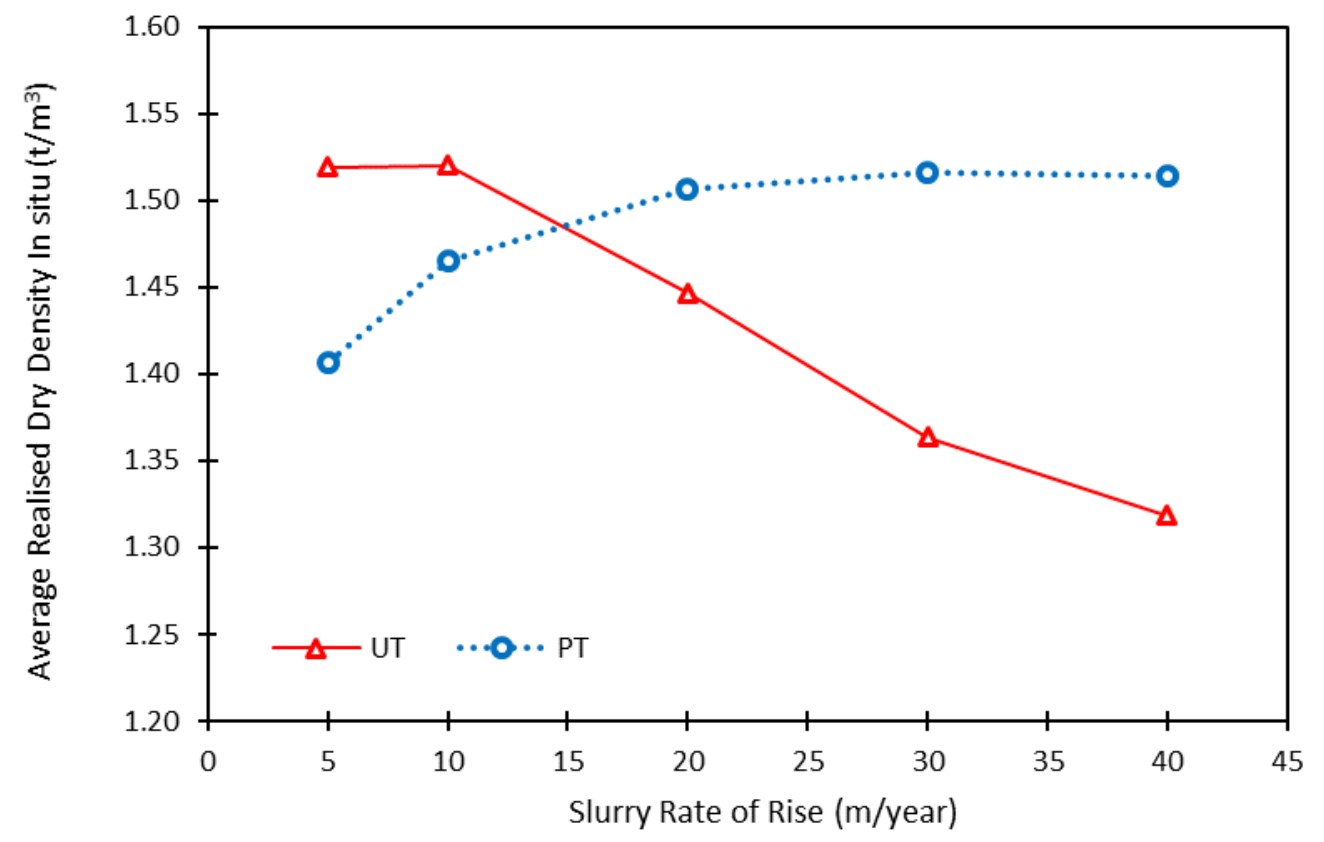

Figure 4 Average dry densities at a range of deposition rates (after Reid et al. 2015b)

\section{$4 \quad$ Context on the magnitude of PT-induced changes}

Whereas clear evidence has been provided by many authors cited in this paper of the changes in geotechnical behaviour that can result from PT, some context from other areas of the geotechnical literature is useful. For example, changes of similar or greater magnitude to those resulting from PT have been demonstrated through changes to the pore fluid chemistry of clayey slurries during preparation and hindered settling. For example, salinity, $\mathrm{pH}$ and other pore fluid chemistry changes have been shown to result in significant changes to consolidation behaviour and shear strength (Sachan \& Penumadu 2007) and potentially the resulting CSL of the materials (Wang \& Siu 2006). As such, the potential for PT to change geotechnical properties should be viewed in the context of the other studies. Indeed, the sensitivity of behaviour to relatively slight pore fluid chemistry changes raises a number of other important questions regarding laboratory testing methods and their applicability to field conditions that the authors would suggest are sometimes not considered.

\section{$5 \quad$ Areas of future study}

As indicated in this paper, a significant amount of research has occurred over the past 20 years to better understand the effects of PT on geotechnical properties of slurries. However, there remain a number of issues that require further consideration:

- Penetrometer response: Owing to the limitations of miniature penetrometers, and attempting to correlate behaviours in situ (where materials used in the comparison are never 'identical'), it is still unknown how well standard interpretation methods will work in a PT deposit. 
- Ageing: Some experimental studies suggest that destruction of the polymers themselves (after settling and consolidation - i.e. fabric development) changed the geotechnical properties of the material. The potential for ageing or long-term degradation of polymers in situ has not been sufficiently explored.

- Shear effects: At least two studies demonstrate that the significant shearing of a slurry, after PT has occurred, can alter geotechnical properties when compared to a non-sheared sample. Further assessment of this behaviour is necessary.

It is our view that most of these issues could best be assessed by means of joint efforts between mining companies, consultants, chemical suppliers and academia. Each brings a particular skill set and set of resources to the problem. Such a combined effort could be applied on a large scale in studies to use PT to create a steepened tailings beach.

\section{Conclusions}

A review of published data on the geotechnical effects of PT was carried out. A number of laboratory-based comparisons have been made, with an increase in data from in situ testing becoming available as the technology matures and becomes more widespread.

The most common test programs investigated the effects of PT on consolidation characteristics (density and hydraulic conductivity). These test programs generally indicated lower densities following PT after consolidation to a given value of effective stress, along with higher hydraulic conductivities at a given density. These two findings indicate that the effect of PT on actual densities realised in a TSF are a function of the tailings RoR - at higher RoR, the increased hydraulic conductivity resulting from PT generally outweighs the lower final density at a given effective stress. Three examples of numerical modelling exploring such issues were identified in the literature.

A number of test programs investigated the shearing behaviour with and without PT. In general, undrained shear strengths at a given density were higher following PT. This was observed in both field vane shear programs and a wide array of laboratory testing. Consistent with the undrained strength result, there is strong evidence that PT results in a different CSL - an effect of significant importance in liquefaction assessments. The shear rate effects of PT material appeared to be greater, based on one laboratory test program, which was consistent with field versus laboratory comparisons of PT MFT material.

Shearing of the PT material after treatment was seen to generally reduce the effects of PT on consolidation behaviour and shear strength compared to unsheared samples. As shearing of tailings after treatment will occur on all tailings beaches, this factor requires additional consideration.

Penetrometer resistance was seen to change drastically following PT in one field and one centrifuge program that could be found in the literature. These changes appear to be occurring, at least partially, as a result of higher effective stresses in the PT material (owing to faster consolidation), and to greater drainage during penetration. However, based on the limited number of examples, and the complexities induced by penetration under different drainage conditions (partially drained and undrained), further investigation is required.

Limited evidence as to the longevity of polymers in situ, and the stability implications should they degrade, was located. One study indicated that the use of heat to degrade the polymers may have reduced the geotechnical effects of PT. However, this study was carried out on a polymer type not typically used in PT of tailings at the point of discharge. Further study in this area is of importance should steepened beaches be developed using PT technology. 


\section{References}

Adkins, S, Berger, A, Muhor, G, Brodt, G, Flanagan, I, 2012 'BASF novel flocculant technology in dynamic thickening operation', in RJ Jewell, AB Fourie and A Paterson (eds), Proceedings of the 15th International Seminar on Paste and Thickened Tailings, Australian Centre for Geomechanics, Perth, pp. 183-194.

Azam, S 2011, 'Large strain settling behavior of polymer-amended laterite slurries', International Journal of Geomechanics, vol. 11, no. 2, pp. 105-112.

Backer, RR \& Busch, RA 1981, Fine Coal Refuse Slurry Dewatering, United States Department of the Interior, Bureau of Mines, Washington, DC.

Beier, N, Wilson, W, Dunmola, A \& Sego, D 2013, 'Impact of flocculation-based dewatering on the shear strength of oil sands fine tailings', Canadian Geotechnical Journal, vol. 50, no. 9, pp. 1001-1007.

Beveridge, A, Mutz, P \& Reid, D 2015, 'Tailings co-disposal case study - art or science?', in RJ Jewell and AB Fourie (eds), Proceedings of the 18th Seminar on Paste and Thickened Tailings, Australian Centre for Geomechanics, Perth, pp. 505-520.

Castro, G 2003, 'Evaluation of seismic stability of tailings dams', in P Culligan, H Einstein and A Whittle (eds), Proceedings of Soils and Rock American 2003: 12th Pan-American Conference on Soil Mechanics and Geotechnical Engineering, Verlag Glückauf GmbH, Essen, pp. 2229-2234.

Charlebois, LE 2012, On the Flow and Beaching Behaviour of Sub-aerially Deposited, Polymer-flocculated Oil Sands Tailings: A Conceptual and Energy-based Model, MAppSc thesis, University of British Columbia, Vancouver.

Cooling, D \& Beveridge, A 2015, 'Use of Rheomax ${ }^{\circledR}$ ETD technology to thicken bauxite residual slurry during super thickener bypass', in RJ Jewell and AB Fourie (eds), Paste and Thickened Tailings - A Guide, 3rd edn, Australian Centre for Geomechanics, Perth, pp. 311-313.

Da Silva, F 2011, 'Reducing risks to tailings storage facilities through in-line flocculation', in J Han and DE Alzamora (eds), Proceedings of GeoFrontiers 2011: Advances in Geotechnical Engineering, American Society of Civil Engineers, Reston, pp. 2937-2946.

Farrow, J, Johnston, R, Simic, K \& Swift, J 2000, 'Consolidation and aggregate densification during gravity thickening', Chemical Engineering Journal, vol. 80, no. 1-3, pp. 141-148.

Finnie, IMS \& Randolph, MF 1994, 'Punch-through and liquefaction induced failure of shallow foundations on calcareous sediments', Proceedings of the 7th International Conference on Behavior of Offshore Structures (BOSS '94), Pergamon, Cambridge, pp. 217-230.

Gholami, R \& Simms, P 2015, 'Shear behaviour in element testing of polymer amended mature fine tailings', Proceedings of the 68th Canadian Geotechnical Conference, Canadian Geotechnical Society, Richmond.

Gladman, B, de Kretser, RG, Rudman, M \& Scales, PJ 2005, 'Effect of shear on particulate suspension dewatering', Chemical Engineering Research \& Design, vol. 83, no. 7, pp. 933-936.

Gladman, B, Rudman, M \& Scales, PJ 2010, 'The effect of shear on gravity thickening: Pilot scale modelling', Chemical Engineering Science, vol. 65, no. 14, pp. 4293-4301.

Jeeravipoolvarn, S, Scott, J \& Chalaturnyk, R 2009, 'Geotechnical characteristics of laboratory in-line thickened oil sands tailings', Proceedings of Tailings and Mine Waste 2009, Information Technology, Creative Media, Vancouver, pp. 813-828.

Jeeravipoolvarn, S, Scott, D, Chalaturnyk, R \& Shaw, B 2014, 'Effect of pipeline shear on consolidation properties of oil sands fine tailings', Proceedings of Tailings and Mine Waste 2014, Information Technology, Creative Media, Vancouver, pp. 495-506.

Li, AL, Been, K, Ritchie, D \& Welch, D 2009, 'Stability of large thickened, non-segregated tailings slopes', in RJ Jewell, AB Fourie, $S$ Barrera and J Wiertz (eds), Proceedings of the 12th International Seminar on Paste and Thickened Tailings, Australian Centre for Geomechanics, Perth, pp. 301-312.

Manzotti, A, Van Impe, P, Van Impe, W \& Fratalocchi, E 2014, 'Impact of flucculants on the stress-strain behaviour of dredged sediments', in B Abdulmalek, ST Yuen and B Brown (eds), Proceedings of the 7th International Congress on Environmental Geotechnics, Engineers Australia, Barton, pp. 650-656.

Mao, X \& Fahey, M 1999, 'A method of reconstituting an aragonite soil using a synthetic flocculant', Géotechnique, vol. 49, no. 1, pp. 15-32.

McPhail, GI, Noble, A, Papageorgiou, G \& Wilkinson, D 2004, 'Development and implementation of thickened tailings discharge at Osborne Mine, Queensland, Australia', Proceedings of the Seventh International Seminar on Paste and Thickened Tailings, Australian Centre for Geomechanics, Perth.

Olson, SM \& Stark, TD 2002, 'Liquefied strength ratio from liquefaction flow failure case histories', Canadian Geotechnical Journal, vol. 39, no. 3, pp. 629-647.

Reid, D \& Boshoff, J 2015, 'Stability of a proposed steepened beach', in RJ Jewell and AB Fourie (eds), Proceedings of the 18th International Seminar on Paste and Thickened Tailings, Australian Centre for Geomechanics, Perth, pp. 181-294.

Reid, D \& Fourie, AB 2012, 'The effects of synthetic flocculants on some geotechnical properties of kaolin clay', in RJ Jewell, AB Fourie, and A Paterson (eds), Proceedings of the 15th International Seminar on Paste and Thickened Tailings, Australian Centre for Geomechanics, Perth, pp. 157-168.

Reid, D \& Fourie, AB 2014, 'Assessing the post-liquefaction shear strength of thickened tailings in the design stage - a review and update', in RJ Jewell, AB Fourie, PS Wells and D van Zyl (eds), Proceedings of the 17th International Seminar on Paste and Thickened Tailings, Australian Centre for Geomechanics, Perth, pp. 429-444.

Reid, D \& Fourie, AB 2015, 'Effects of shear on the behaviour of polymer-treated slurries', in FR Nejad (ed.), Proceedings of Tailings and Mine Waste Management for the 21st Century, The Australasian Institute of Mining and Metallurgy, Melbourne, pp. 215-224. 
Reid, D \& Fourie, AB 2016, 'Laboratory assessment of the effects of polymer treatment on geotechnical properties of low plasticity soil slurry', Canadian Geotechnical Journal, vol. 53, no. 10, pp. 1718-1730.

Reid, D \& Fourie, AB 2017a, 'Effects of polymer treatment on undrained strengths and cyclic behavior of a low-plasticity slurry', Journal of Geotechnical and Geoenvironmental Engineering, vol. 143, no. 6, http://dx.doi.org/10.1061/(ASCE)GT.19435606.0001660

Reid, D \& Fourie, AB 2017b, 'Centrifuge assessment of the effects of polymer treatment on penetrometer response', International Journal for Numerical and Analytical Methods in Geomechanics, under review.

Reid, D, Fanni, R \& Kulessa, M 2015a, 'Cyclic and post-cyclic behaviour of four Australian tailings', in FR Nejad (ed.), Proceedings of Tailings and Mine Waste Management for the 21st Century, The Australasian Institute of Mining and Metallurgy, Melbourne, pp. 207-214.

Reid, D, Utting, L \& Fourie, AB 2015b, 'Assessing the effects of polymer treatment: Segregation considerations', Proceedings of Tailings and Mine Waste 2015, The University of British Columbia, Vancouver.

Riley, T, Reid, D \& Utting, L 2015, 'Polymer-modified tailings deposition - ongoing testing and potential storage efficiency opportunities', in RJ Jewell \& AB Fourie (eds), Proceedings of the 18th International Seminar on Paste and Thickened Tailings, Australian Centre for Geomechanics, Perth, pp. 139-152.

Sachan, A \& Penumadu, D 2007, 'Effect of microfabric on shear behavior of kaolin clay', Journal of Geotechnical and Geoenvironmental Engineering, vol. 133, no. 3, http://dx.doi.org/10.1061/(ASCE)1090-0241(2007)133:3(306)

Seddon, KD 2007, 'Post-liquefaction stability of thickened tailings beaches', in AB Fourie \& RJ Jewell (eds), Proceedings of the Tenth International Seminar on Paste and Thickened Tailings, Australian Centre for Geomechanics, Perth, pp. 395-406.

Spehar, R, Kiviti-Manor, A, Fawell, P, Usher, SP, Rudman, M \& Scales, PJ 2015, 'Aggregate densification in the thickening of flocculated suspensions in an un-networked bed', Chemical Engineering Science, vol. 122, pp. 585-595.

Stark, TD, Beaty, MH, Byrne, PM, Castro, G, Walberg, FC, Perlea, VG, Axtell, PJ, Dillon, JC, Empson, WB \& Mathews, DL 2012, 'Seismic deformation analysis of Tuttle Creek Dam', Canadian Geotechnical Journal, vol. 49, no. 3, pp. 323-343.

Stewart, BM, Backer, RR \& Busch, RA 1986, 'Thickening fine coal refuse slurry for rapid dewatering and enhanced safety', United States Department of the Interior, Bureau of Mines, Washington, DC.

Van Impe, P, Barbetti, L \& Van Impe, W 2009, 'Determination of consolidation parameters of dredging and industrial waste sludge', in M Hamza, M Shahien and Y El-Mossallami (eds), Proceedings of the 17th International Conference on Soil Mechanics and Geotechnical Engineering: the Academia and Practice of Geotechnical Engineering, IOS Press, Amsterdam, pp. 261-263.

Wang, YH \& Siu, WK 2006, 'Structure characteristics and mechanical properties of kaolinite soils. II. Effects of structure on mechanical properties', Canadian Geotechnical Journal, vol. 43, no. 6, pp. 601-617.

Yao, Y 2012, 'The effect of flocculant on the geotechnical properties of mature fine tailings: an experimental study', Proceedings of the Third International Oil Sands Tailings Conference, Oil Sands Tailings Research Facility, Edmonton, pp. 1-16.

Znidarcic, D, Adkins, S, Utting, L \& Catling, M 2015, 'Rheomax ETD technology, a laboratory study of application performance and associated geotechnical characteristics for polymer assisted tailings deposition of oil sands MFT', Proceedings of Tailings and Mine Waste 2015, The University of British Columbia, Vancouver. 
